\title{
På resa med prosten i Sunnerbo kontrakt 1749
}

\section{Av Olle Larsson, doktorand i historia}

\author{
Länk till presentation av Olle Larsson
}

\section{Inledning}

Året är 1749. Ute i Europa har det österrikiska tronföljdskriget precis slutat. En våg av upplysningstankar sköljer över kontinenten och flera länder styrs av upplysta despoter. I Preussen regerar Fredrik den store och i Österrike Maria Teresia. I Danmark firar det oldenburgska kungahuset att man suttit på den danska tronen i 300 år.

I Sverige regerar Fredrik I över ett rike befolkat av omkring 2,2 miljoner människor, varav ungefär 426000 bodde i Finland som då utgjorde Sveriges östra rikshalva. 1749 upprättas det så kallade Tabellverket, föregångaren till Statistiska centralbyrån, av Pehr Wargentin och från och med detta år har vi en relativt tillförlitlig befolkningsstatistik över Sverige. Samma år anmodas alla husägare i Stockholm att sätta upp gatlyktor och hålla dem tända under en viss tid av dygnet under den mörka årstiden.[1]

I början av september detta år gav sig kontraktsprosten Petrus Ulmgren ut på sin årliga visitationsresa i Sunnerbo kontrakt i sydvästra Småland.

\section{Den svenska kyrkan vid 1700-talets mitt}

Under loppet av 1600-talet växte en stark luthersk enhetskyrka fram i Sverige. Denna tid kallas ofta ortodoxins era. Det som kanske mer än något annat utmärker århundradet i kyrkligt hänseende, är överhetens strävanden efter enhetlighet i såväl tro som kyrkoliv. Denna kamp kröntes med seger 1686, då en ny kyrkolag satte punkt för den partikularism, det vill säga de regionala skillnader, som tidigare präglat kyrkolivet i landet. Bristen på ett enhetligt regelverk hade fått till följd att de olika stiftens kyrkoliv styrdes av lokala stiftsstadgor, vilket medförde att de olika stiften tillämpade olika ceremonier.[2] Under slutet av århundradet tillkom också en ny katekesutgåva, en ny psalmbok och en ny kyrkohandbok. Tillsammans med kyrkolagen befrämjade detta en ökad likformighet i kyrkolivet.

Under hela 1600-talet ställdes stora krav på att den enskilde höll sig till den rätta läran och tron och under loppet av århundradet utkom flera sk religionsstadgor. Dessa innehöll krav på rättrogenhet och stränga straff väntade den som avföll från den rätta läran. Ända fram till 1860 var straffet för avfall från den evangeliska lutherska tron landsförvisning.

På lokal nivå spelade kyrkan en mycket viktig roll som moralens och sedligheten väktare. Kampen mot utomäktenskaplig sexualitet, vidskepelse och diverse oseder som till exempel brännvinsdrickande och tobaksrökande präglar mycket av tidens kyrkoliv. I denna kamp var folkundervisningen och kyrkotukten viktiga inslag. Folkundervisningens främsta redskap var katekesen som från och med mitten av 1500-talet var folkboken framför andra. Kyrkotukten, det vill säga den kyrkliga rättskipningen, syftade till att genom varningar, förmaningar, stockstraff, kyrkoplikt och bann skapa goda och lydiga undersåtar.[3]

I socknarna intog kyrkoherdarna en stark ställning i egenskap av ordförande på sockenstämman som var en mycket viktig mötesplats på lokal nivå, där beslut som var viktiga för lokalsamhällets invånare fattades. 
Under 1700-talet fortsatte den lutherska ortodoxin att vara härskande. Nu mötte emellertid den svenska kyrkan hot utifrån i form av nya religiösa rörelser som till exempel pietism och herrnhutism. Detta medförde att den religiösa tvångslagstiftningen fortsatte. Den tog sig bland annat uttryck i det sk konventikelplakatet 1726 som riktade sig mot den framträngande pietismen och i 1735 års religionsstadga som kan sägas utgöra kulmen på den svenska religiösa intoleransens historia. En uppluckring av religionslagstiftningen möter vi inte förrän mot slutet av 1700-talet och denna lättnad i religionstvånget riktade sig enbart till de främmande trosbekännare som vistades i riket.

Fortfarande under 1700-talet spelade kyrkan en mycket viktig roll som folkuppfostrare och kyrkotukten var viktig i kampen mot osedlighet och oordning i församlingarna. Precis som under 1600-talet sköttes kyrkotukten på församlings-, kontrakts- och stiftsnivå.[4]

Denna artikel skall handla om prostvisitationerna i Sunnerbo kontrakt 1749 och därför kan det vara lämpligt att titta närmare på vad prostarna skulle syssla med vid sina visitationer enligt 1686 års kyrkolag, som med vissa strykningar och tillägg kom att gälla långt in på 1900-talet.

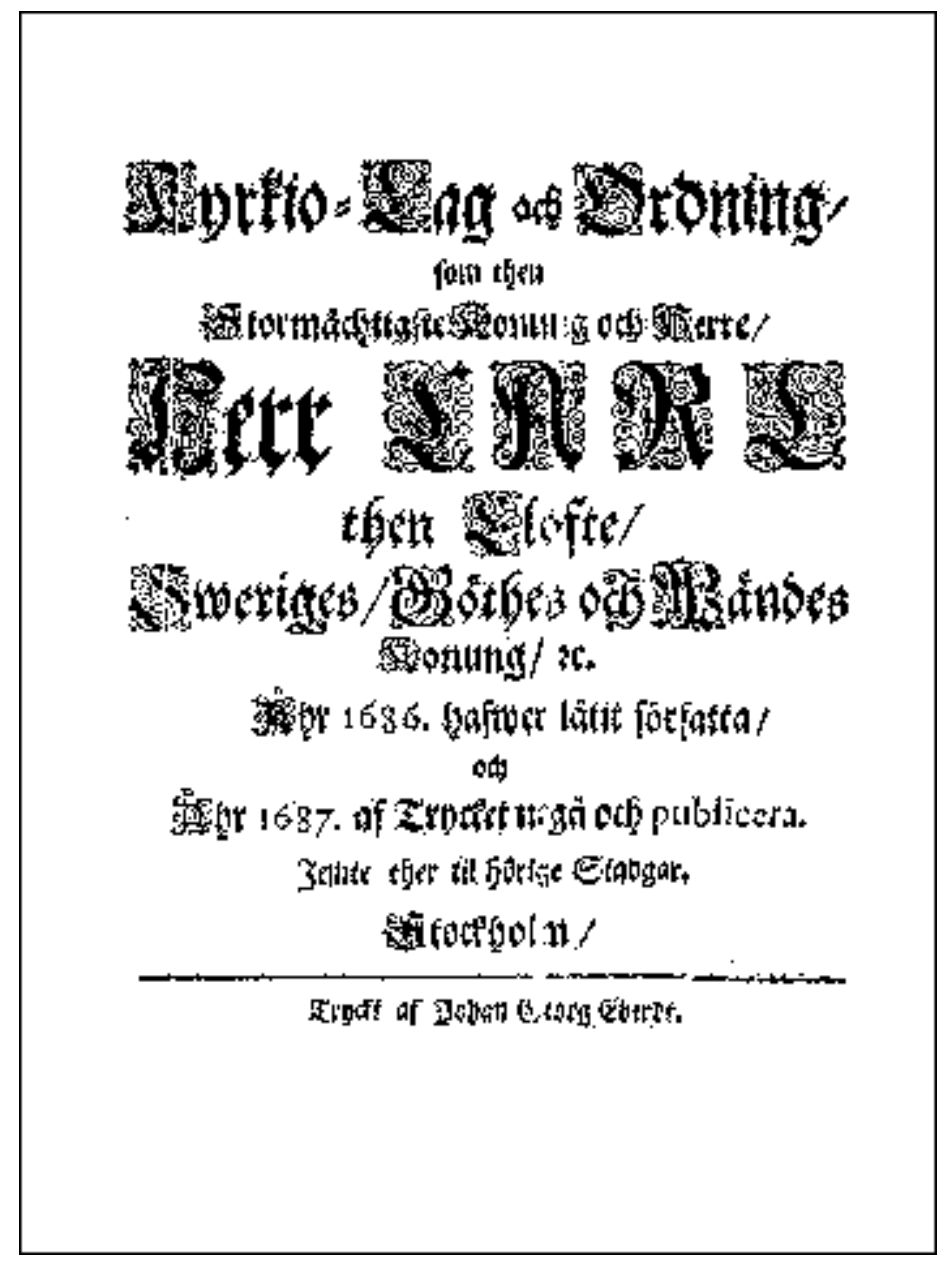

\section{Kyrkolagen och prostvisitationerna}

Enligt 1686 års kyrkolag, som ofta betecknas som den karolinska ortodoxins höjdpunkt i kyrkligt avseende, var en av prostarnas viktigaste uppgifter att årligen visitera de olika församlingarna i det kontrakt de var satta att sköta.[5] I denna lag stadgades att prostvisitationer skulle hållas vid någon lämplig tidpunkt varje år, helst under hösten då tiondet inkommit.

Vid dessa förrättningar skulle prostarna kontrollera en rad olika saker. Det låg inom deras ansvarsområde att se till att katekesundervisningen, kyrkodisciplinen och gudstjänsten sköttes på ett riktigt sätt av det lokala prästerskapet. Vid visitationerna skulle prostarna också förhöra sig om prästernas tionde samt hålla husesyn, varvid kyrkans hus, åkrar och 
ängar skulle besiktigas. Vidare skulle kyrkornas räkenskaper gås igenom och dess ekonomi granskas. Prostarna skulle även kontrollera hur mycket pengar kyrkan hade till sitt förfogande samt att vin- och byggningssäd från församlingen kom kyrkan till godo.

Vid visitationerna var prostarna skyldiga att föra bok. I denna skulle de mål som prosten rannsakade och prövade under sin visitationsresa nedtecknas. De grova syndare som eventuellt kunde finnas i kontraktet skulle införas i boken och deras namn och förseelse noggrant antecknas. En kopia av denna bok skulle förvaras i den aktuella

församlingskyrkan och en annan kopia sändas in till domkapitlet. I svårare mål och sådana så kallade samvetsfrågor, fick prosten inte döma innan han inhämtat biskopens och konsistoriets utlåtande över hur saken skulle behandlas.[6]

Vem var han då, den prost som visiterade i Sunnerbo kontrakt 1749?

\section{Petrus Ulmgren - Kontraktsprost i Sunnerbo}

År 1749 hette prosten i Sunnerbo kontrakt Petrus Ulmgren. Vi vet att han föddes i Växjö i april 1687 och var son till kyrkoherden Lars Ulmgren. Efter studier i Lund, prästvigdes han 1711 och kom då att biträda sin far som då var kyrkoherde i Angelstad. Genom en kunglig fullmakt, utfärdad i Bender av den svenske kungen Karl XII, utsågs han till kyrkoherde i Angelstad och kom därmed att efterträda sin far. Ulmgren utnämndes till kontraktsprost 1748. I Växjö stifts herdaminne beskrivs han som en mycket vaksam och nitisk prästman.

Han hyste ett stort intresse för naturhistoria och skickade en orm till Carl von Linné som denne kom att beskriva i Vetenskapsakademins handlingar 1749.

Ulmgren tjänstgjorde i Angelstad från 1712-55. Han var länge vid god hälsa men kom på sin ålders höst att plågas av svår astma. Ulmgren lämnade jordelivet i november 1755 och efterträddes som kyrkoherde av sin son Erland.[7]

\section{Visitationsakten}

Då Ulmgren kom till de olika församlingarna, inleddes visitationsakten vanligtvis med att gudstjänst förrättades varvid predikan hölls av någon av de lokala prästmännen. Härefter företogs katekesförhör i kyrkan med församlingsborna. Sedan förhöret var avslutat och beröm respektive förmaningar delats ut, fick ungdomarna och kvinnorna tillåtelse att bege sig hemåt.

Därefter steg prästerskapet, klockarna, kyrkvärdarna, sexmännen och eventuella ståndspersoner fram i koret varvid visitationsakten fortsatte. Vid dessa tillfällen var ofta flera av de andra församlingsborna också närvarande, och nu avhandlades de frågor som ansågs vara angelägna.

\section{Verksamheten vid visitationerna}

Detta år visiterade prosten Ulmgren församlingarna i Annerstads, Odensjös, Markaryds, Hallaryds och Göteryds pastorat. Detta innebär att pastoratets samtliga församlingar var närvarande vid dessa förrättningar. Ett pastorat bestod vanligen av en till tre församlingar. Visitationsresan pågick mellan den fjärde och den tjugonde september.

Vid varje visitation togs mellan 14-20 olika ärenden upp till behandling. Vad handlade då dessa ärenden om?

Tabell 1. Verksamheten vid prostvisitationerna i Sunnerbo kontrakt 1749.

Ärende

Kyrkans ekonomi/böcker
Antal ärenden

$29(36 \%)$ 


\begin{tabular}{|c|c|}
\hline Kyrkans byggnader/jord & $6(7 \%)$ \\
\hline Ordningen/religionen i församlingen & $11(14 \%)$ \\
\hline Samlevnaden & $6(7 \%)$ \\
\hline Prästernas ämbetsskötsel/ förhållande med församlingen & $19(23 \%)$ \\
\hline Församlingens undervisning & $5(6 \%)$ \\
\hline Fattigvård & $5(6 \%)$ \\
\hline Totalt: & $81(100 \%)$ \\
\hline
\end{tabular}

Källa: VaLA, VDA, Protokoll från prostvisitationer. Sunnerbo 1749. FIIb:18.

Till kategorin ekonomiärenden har förts de frågor som på något sätt rör kyrkans ekonomi. Detta är den största ärendekategorin och upptar $36 \%$ av den totala ärendemängden. De ekonomiärenden som togs upp till behandling handlade om kontroll av kyrkans räkenskaper, genomgångar av kyrkans inventarier och kontroll av att vin- och byggningssäden inflöt i rätt mängd och vid rätt tidpunkt till kyrkan. Vid prostvisitationerna kontrollerades också att inga av kyrkans pengar lånades ut utan ränta eller riktig pant och prosten utnyttjade också dessa tillfällen till att se till att de böter som tilldömts kyrkan verkligen drevs in. Vid dessa tillfällen diskuterades även tjänstetillsättningar och löner.[8]

De böcker som kontrollerades vid prostvisitationerna var kommunionsböcker, förhörslängder och andra så kallade acta ecclesiastica. I Hallaryd förde kyrkoherden även böcker över sällsamheter som tilldragit sig i naturen och anmärkningsvärda händelser i socknen.[9]

Den näst största ärendekategorin, som utgjorde 23 \% av det totala antalet ärenden, handlade om prästernas ämbetsskötsel. Prosten kontrollerade att gudstjänster, katekesförhör och andra kyrkliga förrättningar ägde rum i rätt tid. Han försökte också se till att sockenstämmor hölls regelbundet och att kyrkoherden årligen läste upp de kungliga plakat och förordningar som han var skyldig att kungöra. Prosten förhörde sig vanligtvis också om förhållandet mellan prästerskap och församlingsbor, vilket oftast var gott.[10]

De ärenden som rörde ordningen i församlingen uppgick till $14 \%$ av den totala mängden ärenden som togs upp till behandling vid prostvisitationerna i Sunnerbo kontrakt 1749. Vid visitationerna frågade vanligen prosten om det fanns några kända syndare $\mathrm{i}$ församlingen.[11] Om det inte fanns några att ange var allt frid och fröjd men angavs någon kunde en rad olika förseelser uppdagas. I Annerstad klagade kyrkoherden över att det var svårt att få församlingsborna att komma till sockenstämmorna och att efterleva de beslut som fattades vid dessa. Han berättade också att han hade problem med soldater och folk som kom från andra orter och slog sig ned i hans församling. Det var inte ovanligt att dessa saknade intyg på sitt leverne från sin hemförsamling. Det var därför svårt för kyrkoherden att veta vilka dessa människor egentligen var.[12] I Markaryd angavs soldaten Nils Flink för stöld och drängen Jöns Larsson som hotat församlingsborna med "eld och brand"[13]. Jag återkommer till dessa personer lite senare.

Ärenden som handlade om kyrkans byggnader och jord utgjorde $7 \%$ av ärendemängden. Vid visitationerna kontrollerade prostarna tillståndet för de kyrkliga byggnaderna i församlingen och eventuella reparationer samt om- och tillbyggnader diskuterades. Ett exempel kan hämtas från Göteryd där prosten kunde konstatera att kyrkan var i gott skick men att taket borde tjäras. Man beslutade att detta skulle ske följande sommar. Vid samma visitation togs också en jordtvist mellan kyrkan och ett järnbruk upp till behandling.[14]

En lika stor andel av ärendemängden upptogs av frågor rörande samlevnaden mellan man och kvinna. Det handlade främst om trolovningar och om personer som levde illa med varandra i sina äktenskap eller hade ingått någon olovlig förbindelse med någon. Ett exempel kan hämtas från Annerstad där det beslutades att inga föräldrar skulle låta sina barn trolovas utan kyrkoherdens vetskap.[15] Ett annat exempel kan hämtas från Markaryd där prosten förhörde sig om dragonen Jöns Persson och Bengta Persdotter som hade ett 
Vid prostvisitationerna togs även församlingsbornas undervisning och de fattigas underhåll upp till behandling. Visitationerna inleddes vanligtvis med ett katekesförhör. Detta var ett sätt för prosten att skaffa sig kunskap om hur det stod till med kristendomskunskaperna i församlingen. Efter förhöret berömdes de som visat sig duktiga, medan de andra förmanades till bättring. Denna ordning följdes vid samtliga församlingar som visiterades i Sunnerbo kontrakt detta år.[17]

En återkommande fråga vid dessa visitationer rörde de fattigas underhåll. Prosten tog tillfället iakt vid visitationerna att förhöra sig om hur de fattiga försörjdes i församlingarna. Ett exempel kan hämtas från visitationen i Odensjö där prosten kunde konstatera att det inte fanns några fattigstugor, men att församlingen försörjde sina fattiga genom ett årligt sammanskott av pengar och spannmål.[18]

Det var alltså en rad olika ärenden som togs upp till behandling vid prostvisitationerna. Men vad kan dessa protokoll berätta för oss om villkoren för de vanliga människorna som levde i Sunnerbo vid 1700-talets mitt? Vilka var människorna som möter oss som ärenden i visitationsakterna? I det följande skall vi se lite närmare på några människoöden sådana som de möter oss genom protokollen från prostens visitationsresa i Sunnerbo kontrakt 1749.

\section{Några människoöden i Sunnerbo vid 1700-talets mitt}

Man säger ofta att det är svårt att komma de vanliga människorna nära i historien. Man talar ibland om dessa människor som den anonyma grå massan. Ur denna massa skall jag lyfta fram några människor som protokollen från prostvisitationerna i Sunnerbo 1749 berättar om. Alla har de det gemensamt att de utmärkt sig på ett negativt sätt. Det är därför vi vet någonting om dem överhuvudtaget. De människor som vi skall möta i det följande är dragonen Jöns Persson och Bengta Persdotter i Markaryd, soldaten Nils Flink i Markaryd, drängen Jöns Larsson i Markaryd samt Måns Mattisson och hans hustru Karin Larsdotter i Hallaryd.

\section{Ett opassande förhållande}

Vid visitationen i Markaryd fick prosten höra om dragonen Jöns Persson och Bengta Persdotter som inlett ett otillåtet förhållande. Problemet var att de var släkt, halvsyskonbarn (halvkusiner) och att kvinnan föregående år övergivit sin man, men inte blivit lagligt skild från honom. Trots detta hade Jöns och Bengta inlett ett sexuellt förhållande och detta hade resulterat i att ett barn fötts.

Kyrkoherden frågade prosten vad han skulle ta sig till med detta par. Prosten menade att de begått en allvarlig synd, varför kronobefallningsmannen Abraham Bergius skulle underrättas om detta så att han kunde dra saken inför världslig rätt. Det beslutades att förhållandet mellan Jöns och Bengta skulle tas upp till behandling vid det stundande hösttinget i Ljungby. Vid detta tillfälle skulle rätten också rannsaka om förhållandet mellan Bengta och den man hon övergivit föregående år. Prosten uppmanade dessutom kyrkoherden att förmana Jöns och Bengta och med hänvisning till Guds ord, framhålla det gudlösa och det skamliga i deras förhållande. Han skulle också se till att de fortsättningsvis inte bodde tillsammans. Om förmaningarna inte hjälpte, skulle kyrkoherden be om kronobetjänternas hjälp att skilja dem åt.

\section{Den tjuvaktige soldaten Flink}

Vid samma visitation angav kyrkoherden soldaten Nils Flink vid södra Sunnerbo kompani för prosten. Denne hade ett drygt år tidigare dömts för stöld av Sunnerbo häradsting men ännu inte utstått sitt straff. Detta innebar att han heller inte genomgått den kyrkliga delen 
av straffet, den sk kyrkoplikten. Detta straff innebar att syndaren under några söndagar fick sitta på en särskild pall på en bestämd plats i kyrkan. Kyrkoplikten kom alltså att fungera som ett sorts skamstraff. Kyrkoherden betecknade soldaten Flink som fräck, då han trots åtskilliga varningar inte låtit bättra sig och försonat sig med Gud och församlingen. Ett brev från länsmannen Magnus Rubb visades upp i vilket denne berättade att soldaten Flink dömts vid 1748 års höstating för att ha stulit en sugga värd fem daler silvermynt från Paul Jönsson. För detta tilltag hade han dömts till trettio daler silvermyt i tjuvnadsbot. Förutom detta straff skulle han också skriftas, avlösas och sitta en söndag på pliktpallen i Markaryds kyrka.

Prosten beslutade att kronobefallningsmannen skulle påminnas att driva in de utdömda böterna så att Flink kunde genomgå sin kyrkoplikt. Om denne trots straffet framhärdade i sin fräckhet och tredska och inga varningar och förmaningar hjälpte, skulle kyrkoherden, genom konsistoriet, begära hjälp från landshövdingen.

\section{Den rasande drängen Jöns}

I Markaryd fick prosten också höra berättelsen om den stackars drängen Jöns Larsson i Lönshult. Han var 25 år gammal och hade i början av år 1747 blivit galen. Församlingen hade då hållit honom under uppsikt. Han hade emellertid återhämtat sig, men vid juletid 1748 hade han fått ett nytt anfall. I tre veckors tid hade han varit alldeles rasande och hotat församlingsborna och deras gårdar med " eld och brand ", varför folket turats om att hålla vakt över honom. Han var nu åter bättre men fortfarande så sinnesvag att han inte kunde förmås att infinna sig vid katekesförhören. Inte heller var det möjligt för prästerna att besöka honom i hemmet eftersom han gav sin hemifrån så snart han fick veta att de tänkte söka upp honom. Kyrkoherden berättade att Jöns var förtvivlad och inte trodde att han längre omfattades av Guds nåd. För sina bristande kristendomskunskapers skull hade han heller inte tillåtits att ta nattvarden. Kyrkoherden berättade att varken han eller någon annan av prästerna försummat att uppsöka denna svagsinta människa. Han bad nu om prostens råd hur man skulle bära sig åt med honom.

Prosten menade att prästerna även fortsättningsvis skulle uppsöka honom och därvid inte låta spara någon möda. De kunde med fördel konsultera kyrkohandbokens sjunde kapitel i vilket beskrivs hur man skall bära sig åt med sjuka människor, främst med sådana som är ängsliga över sin tro och tvivlar på Guds nåd. Dessutom skulle hans grannar förmanas att gå varsamt fram med honom " och icke annat än uppbyggligt och lovligt tal bruka ". Prästerna uppmanades också att hålla förböner för honom.[19]

\section{Måns och Kerstins dåliga äktenskap}

Vid prostvisitationen i Hallaryd blev, efter angivande från kyrkoherden, ett gift par framkallade till prosten för att förhöras om den oenighet som uppkommit dem emellan. Dessa personer var Måns Mattisson och hans hustru Kerstin Larsdotter, som i början av sitt äktenskap levt väl tillsammans med nu blivit ovänner. Trots åtskilliga varningar och förmaningar hade deras kiv och osämja fortsatt och de hade vid flera tillfällen rymt från varandra. Detta var också fallet nu då Måns vistades i Hallaryd och Kerstin i Göteryd. På uppmaning från kyrkoherden hade båda infunnit sig vid denna visitation.

Prosten kungjorde för dem att de var illa ansatta av djävulen, så illa att de trätte med sitt eget kött. Detta var till fördärv för dem själva. Han förklarade sedan att Gud var alla fridsamma äktenskaps beskyddare och att han i sin stora nåd gav dem en tid till att bättra sig och att han skulle vara med dem om de blev sams. Trots detta kunde man bara konstatera att de stod fast i sin " ondska och vedervilja " till varandra.

De tillfrågades sedan om orsaken till deras ovänskap. Var det så att någon av dem misstänkte den andra för att ha varit tillsammans med någon annan? På denna fråga svarade båda nej. 
Måns hävdade att deras osämja berodde på " hennes arga sinne och skamfulla mun ". Hans hustru menade däremot att han inte var ett dugg bättre, i synnerhet inte när han var drucken. Hon berättade att han var mycket begiven på starka drycker och att detta medfört att han slösat bort deras egendom.

Då detta sagts, utbröt ett våldsamt gräl och beskyllningarna haglade genom luften. Prosten hade till en början svårt att få tyst på dem. Karin sade att hon hellre kastade sig i ån än bodde ihop med honom igen. " Ja, hellre vill jag göra av med mig än att vara ihop med dig " svarade mannen. Trots att de varnades och förmanades ville de inte bli sams.

Kyrkoherden berättade att detta ärende angivits för konsistoriet för en tid sedan och härifrån remitterats till Sunnerbo häradsting. Vid tinget hade Måns och Karin förlikats men redan på hemvägen började de åter träta och sedan dess hade de inte bott tillsammans. Han berättade vidare att såväl han som de andra prästerna försökt få dem att bättra sig, men förgäves. De hade, trots sin ovänskap, begärt att få ta nattvarden men detta hade kyrkoherden inte vågat tillåta.

Frågan var nu hur man skulle förfara med dem. I lagens giftermålsbalk stadgades det att då hat och bitterhet rådde mellan man och kvinna och de trots varningar inte bättrat sig, skulle världslig rätt döma i ärendet. Därför skulle tvisten mellan Måns Mattisson och Karin Larsdotter överlämnas till Sunnerbo häradsting så snart som möjligt. Detta var desto mer angeläget eftersom konsistorium redan en gång tidigare remitterat ärendet dit. Man beslutade också att de inte skulle tillåtas att ta nattvarden så länge deras ovänskap bestod.[20]

Hur det gick för dessa människor får vi inte veta genom protokollen. Det skulle emellertid gå att få veta mer om dem om man tittade i domböckerna för Sunnerbo häradsting från den aktuella tiden. Måns Mattisson och Kerstin Larsdotter var närvarande vid visitationen och förde själva sin talan. Dragonen Jöns Persson, Bengta Persdotter, soldaten Nils Flink och drängen Jöns Larsson var inte närvarande då deras fall diskuterades. Trots detta har de avsatt sådana spår i protokollen att det gör det möjligt för oss att komma några människor från 1700-talet mitt lite närmare. Dessa människor som stiger fram ur den grå massans anonymitet är värda en betydligt utförligare historia än vad som kan presenteras här.

\section{(C) Olle Larsson}

\section{Slutkommentarer}

[1] För en översikt över Europas och Sveriges historia under 1700-talet hänvisas till allmänna översiktsverk. Se till exempel Göran Rystad, Europa i världen ca 1500-1700. Expansion och integration. Stockholm, 1997 samt Göran Behre, Lars-Olof Larsson, Eva Österberg, Sveriges historia 1521-1809. Stormaktsdröm och småstatsrealiteter. Stockholm, 1985. För en översikt över utvecklingen i Kronobergs län under den aktuella perioden se Lars-Olof Larsson, Länsstyrelsen och Kronobergs län under 350 år. Växjö, 1984. Mycket lite har skrivits om kyrkliga visitationer i Sverige. Undertecknad behandlar i sitt pågående avhandlingarbete biskopsvisitationerna i Växjö stift under perioden 1650-1760. I denna undersökning kommer ett avsnitt att ägnas åt prostvisitationer. Om prostvisitationer se Carin Bergström, Lantprästen. Prästens funktion i det agrara samhället 1720-1800. OlandFrösåkers kontrakt av ärkestiftet. Kristianstad, 1991. För en forskningsöversikt över andra lokala arenor i lokalsamhället se till exempel Eva Österberg, Svenska lokalsamhällen i förändring ca 1550-1850. Participation, representation och politisk kultur i den svenska självstyrelsen. Ett angeläget forskningsområde. HT 1987.

[2] Ett exempel på en sådan stiftsordning för Växjö stifts vidkommande är den av Petrus Jonae Angermannus författade Cursus Visitationis Dioecesis Wexionensis från 1605. [3] Om kyrkotukten se Jan Sundin, Kontroll, straff och försoning. Kyrklig rättvisa på sockennivå före 1850. Kontroll och kontrollerade. Formell och informell kontroll i ett 
historiskt perspektiv. Umeå, 1982.

[4] För en översikt över svenska kyrkans historia under den aktuella perioden se till exempel Hilding Pleijel, Svenska kyrkans historia. Bd V. Karolinsk kyrkofromhet, pietism och herrnhutism 1680-1772. Uppsala, 1935 eller Erik Petrén, Kyrka och makt. Bilder ur svensk kyrkohistoria. Lund, 1991.

[5] Om kyrkolagstiftningen i Sverige se Sven Kjöllerström, Kyrkolagsproblemet i Sverige 1571-1682. Lund, 1944. Göran Inger, Den svenska kyrkolagen 300 år. Föreläsning vid svenska kyrkohistoriska föreningens årssammankomst 1986. KA 1986. Carl-Gustaf Andrén, Kyrkolagstiftning och kyrkolagsutgivning. KÅ 1986.

[6] 1686 års kyrkolag. Utgiven av samfundet pro fide et christianismo. Uppsala, 1936, sid 89-90.

[7] Om Petrus Ulmgren se Gotthard Virdestam, Växjö stifts herdaminne. Del III. Sunnerbo och Norrvidinge. Växjö, 1929, sid 220-221.

[8] Se till exempel prostvisitationen i Annerstad den fjärde september 1749. VaLA, VDA, Protokoll från prostvisitationer. Sunnerbo 1749. FIIb:18.

[9] Prostvisitationen i Hallaryd den 20 september. VaLA, VDA, Protokoll från prostvisitationer. Sunnerbo 1749. FIIb:18.

[10] Prostvisitationen i Hallaryd den 20 september. VaLA, VDA, Protokoll från prostvisitationer. Sunnerbo 1749. FIIb:18.

[11] Se till exempel prostvisitationen i Odensjö den sjätte september. VaLA, VDA, Protokoll från prostvisitationer. Sunnerbo 1749.

[12] Prostvisitationen i Annerstad den fjärde september. VaLA, VDA, Protokoll från prostvisitationer. Sunnerbo 1749. FIIb:18. Om sockenstämman som lokal arena se till exempel Peter Aronsson, Bönder gör politik. Sockenstämman som social arena i tre smålandssocknar 1680-1850. Lund 1992.

[13] Prostvisitationen i Markaryd den nionde september 1749. VaLA, VDA, Protokoll från prostvisitationer. Sunnerbo 1749. FIIb:18.

[14] Prostvisitationen i Göteryd den tolfte september 1749. VaLA, VDA, Protokoll från prostvisitationer. Sunnerbo 1749. FIIb:18.

[15] Prostvisitationen i Annerstad den fjärde september 1749. VaLA, VDA, Protokoll från prostvisitationer. Sunnerbo 1749. FIIb:18.

[16] Prostvisitationen i Markaryd den nionde september 1749. VaLA, VDA, Protokoll från prostvisitationer. Sunnerbo 1749. FIIb:18.

[17] Se till exempel prostvisitationen i Annerstad den fjärde september 1749. VaLA, VDA, Protokoll från prostvisitationer. Sunnerbo 1749. Fiib:18.

[18] Prostvisitationen i Odensjö den sjätte september. VaLA, VDA, Protokoll från prostvisitationer. Sunnerbo 1749. FIIb:18.

[19] De tre ovanstånde fallen finns beskrivna i protokollet från prostvisitationen i Markaryd den nionde september 1749. VaLA, VDA, Protokoll från prostvisitationer. Sunnerbo 1749. FIIb:18.

[20] Prostvisitationen i Hallaryd den tjugonde september 1749. VaLA, VDA, Protokoll från prostvisitationer. Sunnerbo 1749. FIIb:18. 